\title{
Curcumin induces caspase and calpain-dependent apoptosis in HT29 human colon cancer cells
}

\author{
NISHA SINGH, ANURAAG SHRIVASTAV and RAJENDRA K. SHARMA \\ Department of Pathology and Laboratory Medicine, College of Medicine, University of Saskatchewan, \\ Saskatoon S7N 5E5; Saskatchewan Cancer Agency, Saskatoon S7N 4H4, Saskatchewan, Canada
}

Received October 2, 2008; Accepted January 12, 2009

DOI: $10.3892 / \mathrm{mmr} 00000148$

\begin{abstract}
This study aimed to elucidate the mode of action of curcumin (CCM) as an anticancer agent, and to investigate its effects on the proliferation and induction of apoptosis in HT29 human colon cancer cells. We examined the effect of CCM on two cysteine protease families, namely caspases and calpains, which are known to induce apoptosis in a number of cancer cells. We demonstrated that CCM reduces cell proliferation in $\mathrm{HT} 29$ cells with an $\mathrm{IC}_{50}$ value of $50 \pm 0.015 \mu \mathrm{M}$. Western blot analysis indicated that CCM induced apoptosis in HT2 9 cells by activating the expression of caspases- 3 and -12 , but not caspase-9. CCM also induced apoptosis in these cells through the involvement of calpain. These findings indicate that CCM-induced apoptosis in HT29 cells follows the caspase-12 apoptotic pathway, and also involves calpain.
\end{abstract}

\section{Introduction}

Colorectal cancer is a major cause of morbidity and mortality in western countries (1). The development of diet-derived chemopreventive agents has recently become a popular area in the field of cancer research. Many diet-derived compounds exhibit promising anticancer properties in epidemiological as well as in experimental studies (2).

Curcumin (CCM) is a naturally occurring polyphenolic compound isolated from the rhizomes of the plant Curcuma longa or Curcuma domestica. Turmeric has traditionally been recognized in India, China and other Southeast Asian countries as treatment for various diseases (3), and its active compound, diferuloylmethane, is widely used in Indian medicines (4). CCM displays anti-inflammatory, anticancer and antiviral activities (5-7). Several in vitro studies have demonstrated that CCM inhibits the proliferation of cancer cells by cell cycle

Correspondence to: Dr R.K. Sharma, Saskatchewan Cancer Agency, 20 Campus Drive, Saskatoon S7N 4H4, Saskatchewan, Canada

E-mail: rajendra.sharma@saskcancer.ca

Key words: curcumin, apoptosis, caspases, HT29 colon cancer cells, calpain, calpastatin arrest and induces apoptosis in a variety of cancer cell lines, including HL-60, K562, MCF-7, T98G and HeLa cells (8-10). Furthermore, it has been suggested that CCM suppresses skin, mammary, colon and liver carcinogenesis in a mouse model (11). Although the mechanism of action of CCM as an anticancer agent is not fully understood, the compound is known to activate the mitochondrial-mediated caspase pathway, thus leading to the induction of apoptosis in cancer cells. In Caki cells, CCM deactivated Akt, inhibited Bcl-2, Bcl-XL and IAP, and promoted the mitochondrial release of cytochrome $\mathrm{c}$, activating caspase-3 for apoptosis (12). Similarly, in U937 cells, CCM inhibited Bcl-XL and IAP, but favored cytochrome c release and caspase-3 activation (13). In HL-60 cells, the induction of apoptosis by CCM involved caspase-8mediated Bid cleavage, cytochrome c release and caspase- 3 activation (14). CCM also induced caspase-3-independent apoptosis in Jurkat cells (15) and, in human pancreatic cancer cells, down-regulated $\mathrm{NFKB}$, causing the inhibition of growth and the induction of apoptosis (16).

The anticancer properties of CCM in colon cancer have been demonstrated in vivo and in vitro $(17,18)$. CCM has been shown to inhibit the growth of colon cancer cells by inhibiting cyclooxygenase-2 (COX-2) expression (19). Furthermore, CCM induced apoptosis in HCT116 human colon cancer cells through the JNK signaling pathway (20). Recently, it has been demonstrated that Bax, but not Bak, is a critical regulator of CCM-induced apoptosis (21).

Apoptosis can be triggered by two major pathways, the death receptor-associated extrinsic pathway and the mitochondria-dependent intrinsic pathway $(22,23)$. Caspases, a family of cysteine aspartyl-specific proteases, regulate the initiation and the final execution of apoptosis in both pathways (24). Three main pathways are involved in the activation of the caspase cascade: i) the ligand-activated caspase- 8 pathway, ii) the mitochondrial pathway, which involves cytochrome c as well as apoptosome-associated caspases- 9 and -3 , and iii) the endoplasmic reticulum (ER)-specific apoptotic pathway, which involves caspase-12 activation (25). This novel ERspecific apoptotic pathway is activated by caspase-12 $(26,27)$, which in turn may be activated as a result of its proteolytic cleavage by calpain, a non-caspase protease. Calpain, upon activation by elevated intracellular free $\mathrm{Ca}^{2+}$, is known to translocate from the cytosol to the membrane, where it can cleave procaspase-12 to generate active caspase-12 (28). Active caspase-12 is capable of directly activating caspase- 3 . 
In the present study, we attempted to understand the effect of CCM on HT29 cells and investigated the possible underlying mechanisms behind its induction of apoptosis. To this end, CCM-induced apoptosis in HT29 cells was analyzed, and the activation of caspase proteolytic pathways for apoptosis was explored.

\section{Materials and methods}

Materials. Curcumin, anti- $\beta$-actin antibody, protease inhibitor cocktail for mammalian cell culture, MTT and other analytical grade reagents were purchased from Sigma (Canada). Anticalpain $(m)$ and calpastatin antibodies were purchased from Chemicon International (Canada). Depending on the primary antibody, the secondary antibodies used were either HRPconjugated goat anti-mouse or anti-rabbit IgG obtained from Bio-Rad Laboratories (Canada). Anti-caspases-3, -9 and -12, as well as anti-PARP antibodies, were obtained from Cell Signaling Technology (Canada).

\section{Methods}

Cell culture and treatment of HT29 cells. The human colon cancer cell line HT29 was obtained from the American Type Culture Collection (ATCC) and grown as monolayers at $37^{\circ} \mathrm{C}$ in a humidified atmosphere of $5 \% \mathrm{CO}_{2}$ in Dulbecco's modified Eagle's medium (DMEM) containing 10\% (v/v) heat-inactivated fetal calf serum, penicillin $(50 \mathrm{U} / \mathrm{ml})$ and streptomycin $(50 \mu \mathrm{g} / \mathrm{ml})$. Cells were grown in a $75-\mathrm{mm}$ tissue culture dish at $37^{\circ} \mathrm{C}$ containing $10 \mathrm{ml}$ of DMEM. Following trypsinization, the cells were serially passaged using a trypsin/ EDTA solution. After $80 \%$ confluency was achieved, prior to treatment, the cells were starved for $24 \mathrm{~h}$ in DMEM medium. CCM was dissolved in ethyl alcohol to make a stock solution, aliquoted and stored at $-20^{\circ} \mathrm{C}$. Dose response studies were conducted to determine the $\mathrm{IC}_{50}$ values. HT29 cells were treated with $50 \mu \mathrm{M} \mathrm{CCM}$ for $48 \mathrm{~h}$ for the induction of apoptosis.

Western blot analysis. After the treatments, cells were washed with PBS and lysed on ice using $1 \mathrm{ml}$ of lysis buffer containing $50 \mathrm{mM}$ HEPES (pH 7.4), $50 \mathrm{mM}$ sucrose, $20 \mathrm{mM}$ sodium orthovanadate, $50 \mathrm{mM}$ sodium fluoride, $50 \mu \mathrm{M}$ leupeptin, $1 \%$ aprotinin, $2 \mathrm{mM}$ EDTA, $0.1 \%$ SDS and $1 \mathrm{mM}$ PMSF. The cells were scraped off the plates and kept on ice for $30 \mathrm{~min}$. Samples were then centrifuged at $13,000 \mathrm{xg}$ for $3 \mathrm{~min}$ at $4^{\circ} \mathrm{C}$, and the supernatants were stored at $-80^{\circ} \mathrm{C}$ until use. Proteins $(20 \mu \mathrm{g})$ were resolved by SDS-PAGE and transferred to a PVDF membrane. The membranes were blocked with $5 \%$ non-fat dried milk containing $0.02 \%$ Tween-20 for $1 \mathrm{~h}$ at room temperature, probed with the appropriate antibody, then washed and incubated with the appropriate secondary antibody conjugated to HRP for $1 \mathrm{~h}$ at room temperature. After washing, visualization of the polypeptide bands was carried out using a chemiluminescence reagent.

$m$-Calpain activity. The $m$-calpain activity in the cell lysate of treated or untreated HT29 cells was determined using Hammerstein grade casein as a substrate (29). Briefly, the assay mixture consisted of $20 \mathrm{mM}$ imidazole- $\mathrm{HCl}$ buffer containing $5 \mathrm{mM}$ cysteine (pH 7.5), $5 \mathrm{mg}$ casein, either $5 \mathrm{mM}$

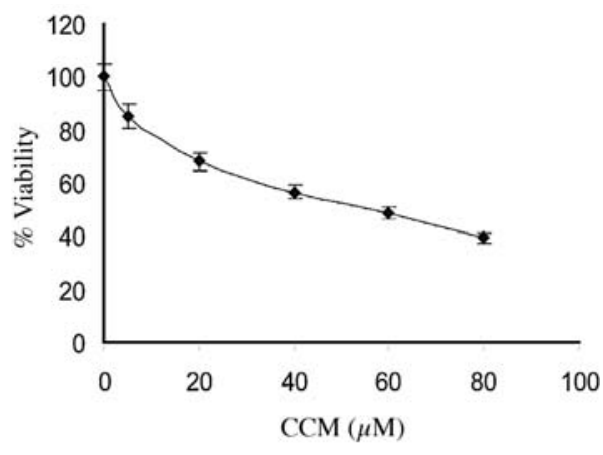

Figure 1. Effect of curcumin (CCM) on the viability of HT29 cells. Cells (1x10 $/$ well) were seeded in a 96-well plate and treated with different concentrations of CCM for $24 \mathrm{~h}$. Cell viability was determined by the MTT assay as described in Materials and methods. Data are the means \pm SD of three independent experiments in triplicate.

$\mathrm{CaCl}_{2}$ or $5 \mathrm{mM}$ EGTA, and the cell lysates. The mixture was incubated at $30^{\circ} \mathrm{C}$ for $30 \mathrm{~min}$.

MTT assay. The MTT assay was carried out to estimate the viability of HT29 cells after incubation with CCM $(0-80 \mu \mathrm{M})$ following a method described by Mosmann (30). Cells were plated onto a 96-well plate at a density of $1 \times 10^{4}$ cells/well in $200 \mu \mathrm{l}$ medium, and were treated with a series of CCM concentrations $(0-80 \mu \mathrm{M})$ for $24 \mathrm{~h}$. After $24 \mathrm{~h}$, the medium containing CCM was carefully removed, and $50 \mu \mathrm{l}$ of MTT solution was added to each well. The plate was then read at a wavelength of $540 \mathrm{~nm}$. Cell viability was considered to be $100 \%$ at the concentration of $0 \mu \mathrm{M}$ CCM.

\section{Results}

In vitro effect of curcumin on the cell viability of HT29 cells. In order to investigate the cytotoxic properties of CCM, we examined the in vitro effects of different concentrations of CCM on the viability of HT29 cells after 24 h using the MTT assay (Fig. 1). CCM inhibited the growth of HT29 cells in a concentration-dependent manner. At the concentration of $50 \pm 0.015 \mu \mathrm{M}, 50 \%$ viability was detected during the $24-\mathrm{h}$ treatment, whereas maximum cytotoxicity was observed at a concentration of $80 \pm 0.017 \mu \mathrm{M}$.

Effect of curcumin on the activity and expression of m-calpain. We used the $\mathrm{IC}_{50}$ concentration of CCM in further studies, with the aim of determining whether calpain is involved in CCM-induced apoptosis in HT29 cells. The $m$-calpain activity in the cell lysates prepared from CCM-treated or untreated cells was determined using Hammerstein grade casein as a substrate. Increased $m$-calpain activity was noted in the cell lysate treated with $50 \mu \mathrm{M}$ CCM (Fig. 2A) as compared to the cells treated with alcohol (positive control) or medium alone (negative control). Furthermore, Western blot analysis revealed the increased expression of $m$-calpain in the CCM-treated cells (Fig. 2B; lane 3) as compared to the controls (Fig. 2B; lanes 1 and 2).

Effect of curcumin on the expression of caspases-3, -9, -12 and PARP. The results from the MTT assay suggest that 


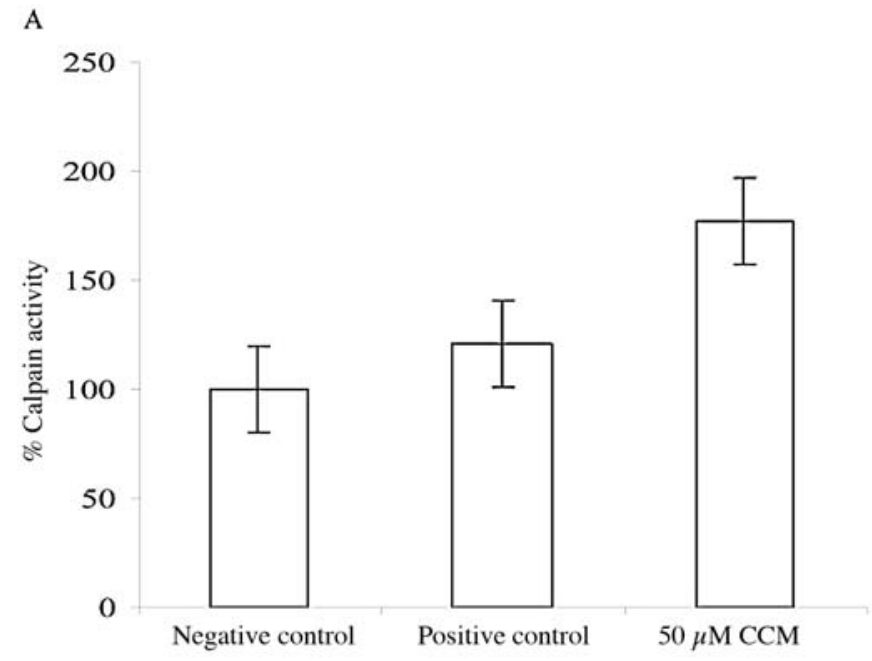

B

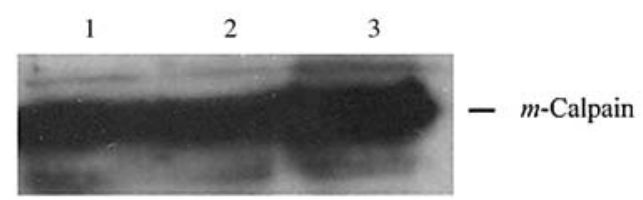

Figure 2. Effect of curcumin on $m$-calpain activity and expression. (A) HT29 cells were treated with $50 \mu \mathrm{M} \mathrm{CCM}$ for $48 \mathrm{~h}$. $m$-Calpain activity was determined in treated and untreated cells using Hammerstein grade casein as a substrate as described in Materials and methods. Data are the means $\pm \mathrm{SD}$ of three independent experiments in triplicate. (B) Protein $(20 \mu \mathrm{g})$ was loaded onto each lane, subjected to SDS-PAGE, transferred onto a nitrocellulose membrane and probed with $m$-calpain antibodies as described in Materials and methods. Lane 1, cells treated in medium alone (-ve control); lane 2, cells treated in medium containing $0.1 \%$ ethanol (+ve control); lane 3 , cells treated in medium containing $50 \mu \mathrm{M} \mathrm{CCM}$.

CCM induces cell death in HT29 cells. To further investigate the mechanism of action of this effect, we examined the expression of the caspases that are the final executioners of apoptosis. Activation of caspase- 3 serves as an early marker of apoptosis in a variety of cell types. We therefore first determined whether caspase- 3 was activated by CCM in HT29 cells. Cells at $80 \%$ confluence were starved and treated with $50 \mu \mathrm{M} \mathrm{CCM}$ for $48 \mathrm{~h}$. Immunoblots of the protein lysates were carried out with anti-caspase-3 antibody (Fig. 3A). To further confirm the activity of caspase- 3 , the cleavage of its substrate, the nuclear enzyme polyADP-ribose polymerase (PARP), was monitored. The caspase-3-directed proteolysis of the native PARP molecule enzyme of molecular mass $116 \mathrm{kDa}$ is detected in immunoblots as an $89-\mathrm{kDa}$ fragment, which acts as a marker of caspase-3 activity (Fig. 3B; lane 3).

Since caspase- 3 is activated by the caspase-9-dependent mitochondrial pathway, we examined the expression and activation of caspase-9 by Western blot analysis (Fig. 3C). No increased expression of caspase- 9 was noted in the CCMtreated groups, suggesting that this mitochondrial apoptosis pathway was not involved in CCM-induced apoptosis in HT29 cells.

As increased activity of calpain and calpain/caspase-12mediated apoptosis in other cell types has previously been reported, we also studied the effect of CCM on caspase- 12 . Expression of caspase-12 was measured by immunoblotting,
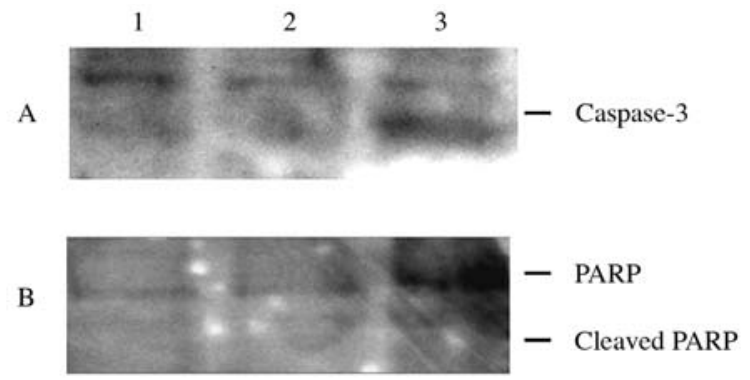

C

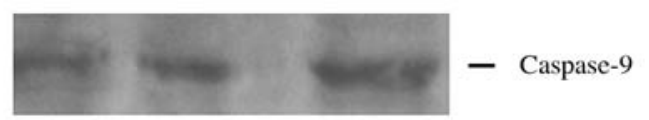

$\mathrm{D}$

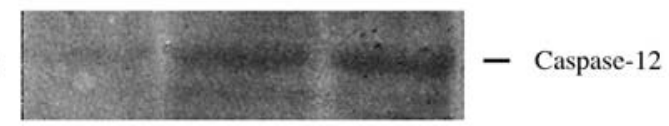

$\mathrm{E}$

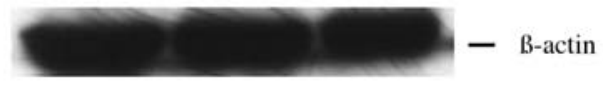

Figure 3. Effect of curcumin on the expression of caspase-3, PARP, caspase-9 and -12 . HT2 2 cells were treated with $50 \mu \mathrm{M}$ CCM for $48 \mathrm{~h}$. Protein $(20 \mu \mathrm{g})$ was loaded onto each lane, subjected to SDS-PAGE, transferred onto a nitrocellulose membrane and probed with caspases-3, -9 and -12, and PARP antibody. (A) Caspase-3; (B) PARP; (C) caspase-9; (D) caspase-12; (E) B-actin antibody, used as a loading control indicator. Lane 1, cells treated in medium alone (-ve control); lane 2, cells treated in medium containing $0.1 \%$ ethanol (+ve control); lane 3 , cells treated in medium containing $50 \mu \mathrm{M}$ CCM.

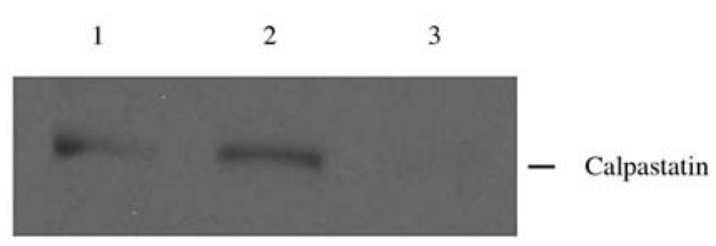

Figure 4. Effect of curcumin on the expression of calpastatin. HT29 cells were treated with $50 \mu \mathrm{M}$ CCM for $48 \mathrm{~h}$. Protein $(20 \mu \mathrm{g})$ was loaded onto each lane, subjected to SDS-PAGE, transferred onto a nitrocellulose membrane and probed with calpastatin antibody. Lane 1, cells treated in medium alone (-ve control); lane 2, cells treated in medium containing $0.1 \%$ ethanol (+ve control); lane 3, cells treated in medium containing $50 \mu \mathrm{M} \mathrm{CCM}$.

which revealed an increase in caspase-12 expression after CCM treatment (Fig. 3D; lane 3). This suggests that there was an upregulation in the expression levels of 55-kDa caspase-12 after $48 \mathrm{~h}$ of CCM treatment, indicating that caspase-12 plays an important role in CCM-induced apoptosis in HT29 cells.

In vitro effect of curcumin on the expression of calpastatin. The proteolytic activity of calpain is controlled by calpastatin, a known endogenous inhibitor of calpain that may be degraded by calpain and caspases during apoptosis (31). We examined the effect of CCM on calpastatin levels. Western blot analysis revealed a decrease in the expression of calpastatin in CCMtreated HT29 cells (Fig. 4, lane 3), indicating that CCM diminishes the expression of calpastatin in HT29 cells while increasing the expression and activity of $m$-calpain (Fig. 2A and B). 


\section{Discussion}

Plant-derived agents have attracted extensive attention due to their anticancer and antibacterial effects $(32,33)$. The most extensively characterized studies have involved the antitumor effects of these agents, in which several characteristic phenomena of apoptosis were observed, such as cell cycle arrest, DNA damage and the activation of caspases $(34,35)$. In this investigation, we demonstrated that CCM can effectively induce apoptosis via the activation of proteolytic pathways in human colon cancer HT29 cells. CCM is a hydrophobic polyphenolic compound that moves into the cytosol through the plasma membrane (35). This phenolic compound inhibits carcinogenesis, and has been demonstrated to inhibit the proliferation of many human cancer cell lines in vitro.

The present study demonstrated that CCM inhibits the growth of HT29 colon adenocarcinoma cells in a concentrationdependent manner. Maximum cytotoxicity was observed at the highest concentration of $80 \pm 0.017 \mu \mathrm{M}$ (Fig. 1). In concordance with our results, a previous report showed the same type of inhibitory effect after a 72-h treatment (36). Furthermore, CCM has previously been reported to have similar cell growthinhibiting effects on other colon cancer cell lines (37).

Although previous studies have implicated CCM in the apoptosis of the HT29 cell line, the molecular and cellular mechanisms involved in this process have not been fully elucidated. Exposure to CCM for up to $48 \mathrm{~h}$ was found to induce apoptosis in HT29 cells, as evidenced by the activation of caspase-3, a key protease in the execution of apoptosis. There are several routes by which caspase- 3 is activated. One is through the release of mitochondrial cytochrome $\mathrm{c}$, the formation of the apoptosome and the activation of caspase-9, which in turn activates the effector caspase-3. Notably, the initiator caspase-9 did not show any activation under similar conditions (Fig. 3C). Our observation of the CCM-mediated activation of caspase-9 leading to apoptosis did not correlate with that of previous studies, conducted on other human colon cancer cells $(21,38)$, squamous cell lung carcinoma and Caki cells (12).

It has previously been reported that a novel $\mathrm{Ca}^{2+}$-mediated calpain/caspase-12-dependent apoptotic pathway exists in breast cancer cells (39). Our findings provide evidence that the CCM treatment of HT29 cells activated the expression of caspase-12 (Fig. 3D), and additionally increased calpain activity (Fig. 2A). Calpain, a neutral $\mathrm{Ca}^{2+}$-dependent cysteine protease, also plays an important role in apoptosis (40). It has been demonstrated that, in apoptotic cells, cooperation between calpain and caspase-3 exists (40). In this study, we also observed that CCM activated the expression of caspase-3 and calpain. Furthermore, expression of calpastatin, an endogenous inhibitor of calpain, was downregulated in the CCMtreated group. These results indicate that CCM induced apoptosis in HT29 cells by means of the caspase/calpain pathway. Increased calpain activity resulted due to the downregulation of calpastatin. This suggests that activation of the apoptotic pathway by CCM in HT29 cells may have resulted due to the perturbation of calcium homeostasis.

In conclusion, this study provides initial evidence that CCM-mediated apoptosis in the HT29 colon cancer cell line occurs via the calpain/caspase-12 apoptotic pathway.

\section{Acknowledgements}

This work was supported by the Canadian Institute of Health Research, Canada. We are thankful to Dr J.R. Dimmock, College of Pharmacy and Nutrition, University of Saskatchewan, for the reading of this manuscript.

\section{References}

1. Labianca R, Beretta G, Gatta G, De Braud F and Wils J: Colon cancer. Crit Rev Oncol Hematol 51: 145-170, 2004.

2. Kelloff GJ, Crowell JA, Steele VE, et al: Progress in cancer chemoprevention: development of diet-derived chemopreventive agents. J Nutr 130: 467S-471S, 2000.

3. World Health Organization: Rhizoma Curcumae Longae. In: WHO Monographs on Selected Medicinal Plants. Vol 1. World Health Organization, Geneva, pp115-124, 1999.

4. HemaIswarya $S$ and Doble M: Potential synergism of natural products in the treatment of cancer. Phytother Res 20: 239-249, 2006.

5. Tomita M, Kawakami H, Uchihara JN, et al: Curcumin suppresses constitutive activation of AP- 1 by downregulation of JunD protein in HTLV-1-infected T-cell lines. Leuk Res 30: 313-321, 2006.

6. Oyama Y, Masuda T, Nakata M, Chikahisa L, Yamazaki Y, Miura $\mathrm{K}$ and Okagawa M: Protective actions of 5'-n-alkylated curcumins on living cells suffering from oxidative stress. Eur J Pharmacol 360: 65-71, 1998.

7. Piper JT, Singhal SS, Salameh MS, Torman RT, Awasthi YC and Awasthi S: Mechanisms of anticarcinogenic properties of curcumin: the effect of curcumin on glutathione linked detoxification enzymes in rat liver. Int J Biochem Cell Biol 30: 445-456, 1998.

8. Roy M, Chakraborty S, Siddiqi M and Bhattacharya RK: Induction of apoptosis in tumor cells by natural phenolic compounds. Asian Pac J Cancer Prev 3: 61-67, 2002.

9. Karmakar S, Banik NL, Patel SJ and Ray SK: Curcumin activated both receptor-mediated and mitochondria-mediated proteolytic pathways for apoptosis in human glioblastoma T98G cells. Neurosci Lett 407: 53-58, 2006.

10. Karunagaran D, Rashmi R and Kumar TR: Induction of apoptosis by curcumin and its implications for cancer therapy. Curr Cancer Drug Targets 5: 117-129, 2005.

11. Li L, Aggarwal BB, Shishodia S, Abbruzzese J and Kurzrock R: Nuclear factor-kappaB and IkappaB kinase are constitutively active in human pancreatic cells, and their down-regulation by curcumin (diferuloylmethane) is associated with the suppression of proliferation and the induction of apoptosis. Cancer 101: 2351-2362, 2004.

12. Woo JH, Kim YH, Choi YJ, et al: Molecular mechanisms of curcumin-induced cytotoxicity: induction of apoptosis through generation of reactive oxygen species, down-regulation of Bcl$\mathrm{XL}$ and IAP, the release of cytochrome $\mathrm{c}$ and inhibition of Akt. Carcinogenesis 24: 1199-1208, 2003.

13. Bae JH, Park JW and Kwon TK: Ruthenium red, inhibitor of mitochondrial $\mathrm{Ca}^{2+}$ uniporter, inhibits curcumin-induced apoptosis via the prevention of intracellular $\mathrm{Ca}^{2+}$ depletion and cytochrome c release. Biochem Biophys Res Commun 303: 1073-1079, 2003.

14. Anto RJ, Mukhopadhyay A, Denning K and Aggarwal BB: Curcumin (diferuloylmethane) induces apoptosis through activation of caspase- 8 , BID cleavage and cytochrome c release: its suppression by ectopic expression of $\mathrm{Bcl}-2$ and $\mathrm{Bcl}-\mathrm{xl}$. Carcinogenesis 23: 143-150, 2002.

15. Duvoix A, Blasius R, Delhalle S, et al: Chemopreventive and therapeutic effects of curcumin. Cancer Lett 223: 181-190, 2005.

16. Notarbartolo M, Poma P, Perri D, Dusonchet L, Cervello M and D'Alessandro N: Antitumor effects of curcumin, alone or in combination with cisplatin or doxorubicin, on human hepatic cancer cells. Analysis of their possible relationship to changes in NF-kB activation levels and in IAP gene expression. Cancer Lett 224: 53-65, 2005.

17. Kawamori T, Lubet R, Steele VE, Kelloff GJ, Kaskey RB, Rao CV and Reddy BS: Chemopreventive effect of curcumin, a naturally occurring anti-inflammatory agent, during the promotion/ progression stages of colon cancer. Cancer Res 59: 597-601, 1999. 
18. Huang MT, Wang ZY, Georgiadis CA, Laskin JD and Conney AH Inhibitory effects of curcumin on tumor initiation by benzo[a] pyrene and 7,12-dimethylbenz[a]anthracene. Carcinogenesis 13: 2183-2186, 1992.

19. Goel A, Boland CR and Chauhan DP: Specific inhibition of cyclooxygenase-2 (COX-2) expression by dietary curcumin in HT-29 human colon cancer cells. Cancer Lett 172: 111-118, 2001.

20. Collett GP and Campbell FC: Curcumin induces c-jun Nterminal kinase-dependent apoptosis in HCT116 human colon cancer cells. Carcinogenesis 25: 2183-2189, 2004.

21. Rashmi R, Kumar S and Karunagaran D: Human colon cancer cells lacking Bax resist curcumin-induced apoptosis and Bax requirement is dispensable with ectopic expression of Smac or downregulation of Bcl-XL. Carcinogenesis 26: 713-723, 2005.

22. Adams JM: Ways of dying: multiple pathways to apoptosis. Genes Dev 17: 2481-2495, 2003.

23. Shi Y: Mechanical aspects of apoptosome assembly. Curr Opin Cell Biol 18: 677-684, 2006.

24. Earnshaw WC: Apoptosis. A cellular poison cupboard. Nature 397: 387-389, 1999

25. Yoneda T, Imaizumi K, Oono K, Yui D, Gomi F, Katayama T and Tohyama M: Activation of caspase-12, an endoplastic reticulum (ER) resident caspase, through tumor necrosis factor receptorassociated factor 2-dependent mechanism in response to the ER stress. J Biol Chem 276: 13935-13940, 2001.

26. Nakagawa T and Yuan J: Cross-talk between two cysteine protease families. Activation of caspase-12 by calpain in apoptosis. J Cell Biol 150: 887-894, 2000.

27. Nakagawa T, Zhu H, Morishima N, Li E, Xu J, Yankner BA and Yuan J: Caspase-12 mediates endoplasmic-reticulumspecific apoptosis and cytotoxicity by amyloid-beta. Nature 403: 98-103, 2000.

28. Suzuki K, Imajoh S, Emori Y, Kawasaki H, Minami Y and Ohno S: Calcium-activated neutral protease and its endogenous inhibitor. Activation at the cell membrane and biological function. FEBS Lett 220: 271-277, 1987.

29. Kakkar R, Raju RV, Mellgren RL, Radhi J and Sharma RK: Cardiac high molecular weight calmodulin binding protein contains calpastatin activity. Biochemistry 36: 11550-11555, 1997.
30. Mosmann T: Rapid colorimetric assay for cellular growth and survival: application to proliferation and cytotoxicity assays. J Immunol Methods 65: 55-63, 1983.

31. Wang KK, Posmantur R, Nadimpalli R, et al: Caspase-mediated fragmentation of calpain inhibitor protein calpastatin during apoptosis. Arch Biochem Biophys 356: 187-196, 1998.

32. Gupta S, Afaq F and Mukhtar H: Involvement of nuclear factorkappa B, Bax and Bcl-2 in induction of cell cycle arrest and apoptosis by apigenin in human prostate carcinoma cells. Oncogene 21: 3727-3738, 2002.

33. Gupta S, Hussain T and Mukhtar H: Molecular pathway for (-)epigallocatechin-3-gallate-induced cell cycle arrest and apoptosis of human prostate carcinoma cells. Arch Biochem Biophys 410: $177-185,2003$

34. Tan X, Hu D, Li S, Han Y, Zhang Y and Zhou D: Differences of four catechins in cell cycle arrest and induction of apoptosis in LoVo cells. Cancer Lett 158: 1-6, 2000.

35. Saeki K, Sano M, Miyase T, Nakamura Y, Hara Y, Aoyagi Y and Isemura M: Apoptosis-inducing activity of polyphenol compounds derived from tea catechins in human histiolytic lymphoma U937 cells. Biosci Biotechnol Biochem 63: 585-587, 1999.

36. Aggarwal BB, Kumar A and Bharti AC: Anticancer potential of curcumin: preclinical and clinical studies. Anticancer Res 23: 363-398, 2003.

37. Song G, Mao YB, Cai QF, Yao LM, Ouyang GL and Bao SD: Curcumin induces human HT-29 colon adenocarcinoma cell apoptosis by activating $\mathrm{p} 53$ and regulating apoptosis-related protein expression. Braz J Med Biol Res 38: 1791-1798, 2005.

38. Rashmi R, Kumar S and Karunagaran D: Ectopic expression of Hsp70 confers resistance and silencing its expression sensitizes human colon cancer cells to curcumin-induced apoptosis. Carcinogenesis 25: 179-187, 2004.

39. Sergeev IN: Genistein induces $\mathrm{Ca}^{2+}{ }_{-}$-mediated, calpain/caspase-12dependent apoptosis in breast cancer cells. Biochem Biophys Res Commun 321: 462-467, 2004.

40. Neumar RW, Xu YA, Gada H, Guttmann RP and Siman R: Cross-talk between calpain and caspase proteolytic systems during neuronal apoptosis. J Biol Chem 278: 14162-14167, 2003. 